\title{
Oligometastatic Growing Teratoma Syndrome: A Case for an Aggressive Surgical Approach
}

\author{
William S. Gange ${ }^{a}$ Robert H. Blackwell ${ }^{a} \quad$ John Biemer ${ }^{b} \quad$ Güliz A. Barkan ${ }^{b}$ \\ Maria M. Picken ${ }^{\mathrm{a}, \mathrm{b}} \quad$ Marcus L. Quek ${ }^{\mathrm{a}}$
}

Departments of Urology a and Pathology ${ }^{\mathrm{b}}$, Loyola University Medical Center, Maywood, III. USA

\section{Key Words}

Teratoma • Oncologic surgery • Chemotherapy • Metastasis • Nonseminomatous germ cell tumor

\begin{abstract}
Growing teratoma syndrome is an infrequent presentation of testicular cancer. We present a case of growing teratoma syndrome in a patient who initially presented with clinical stage I nonseminomatous testicular germ cell tumor, who subsequently developed large volume oligometastases to the retroperitoneum, thorax, and thigh. Despite two regimens of chemotherapy, his disease progressed. Complete surgical extirpation of all gross tumors confirmed mature teratoma. An aggressive surgical approach, including postchemotherapy resection of all known metastatic sites, can provide long-term disease-free survival.
\end{abstract}

Copyright $\odot 2015$ S. Karger AG, Basel

KARGER

Fax +4161306 1234

E-Mail karger@karger.ch

www.karger.com
(C) 2015 S. Karger AG, Basel

1015-9770/15/0093-0163\$38.00/0

Accessible online at:

www.karger.com/cur
A 47-year-old gentleman underwent radical orchiectomy for a $10 \mathrm{~cm}$ clinical stage I nonseminomatous germ cell tumor (composed of $65 \%$ yolk sac, $30 \%$ mature teratoma, $<5 \%$ embryonal carcinoma components). He was lost to follow-up but presented 4 years later with shortness of breath and a posterior right thigh mass. Tumor markers were normal and cross-sectional imaging confirmed metastatic disease involving the left hemithorax, retroperitoneum, and right thigh (fig. 1-3). Despite two chemotherapy regimens (bleomycin/etoposide/cisplatin and vinblastine/ifosfamide/cisplatin), interval growth was noted at each site.

He underwent retroperitoneal lymphadenectomy with concomitant left nephrectomy and inferior vena caval tumor thrombectomy to clear the retroperitoneal disease. Subsequent staged resection of the left thoracic and right thigh masses were then performed over the next 8 months. All specimens were composed of solid and cystic components, and microscopically confirmed as mature teratoma (fig. 1c, 2c, 3c). He remains disease-free now nearly 2 years following his last surgery.

Teratoma is known to be resistant to standard chemotherapy and radiation [1]. If not treated appropriately, rapid local tumor growth and malignant degeneration may contribute to significant morbidity and mortality from the disease [2]. The present case highlights the importance of an aggressive surgical approach in which all known metastatic sites are addressed [3].

William S. Gange

MS3, Loyola Stritch School of Medicine

2160 S First Avenue, Building 54, Room 237A

IL-60153, Maywood (USA)

E-Mailwgange@luc.edu 

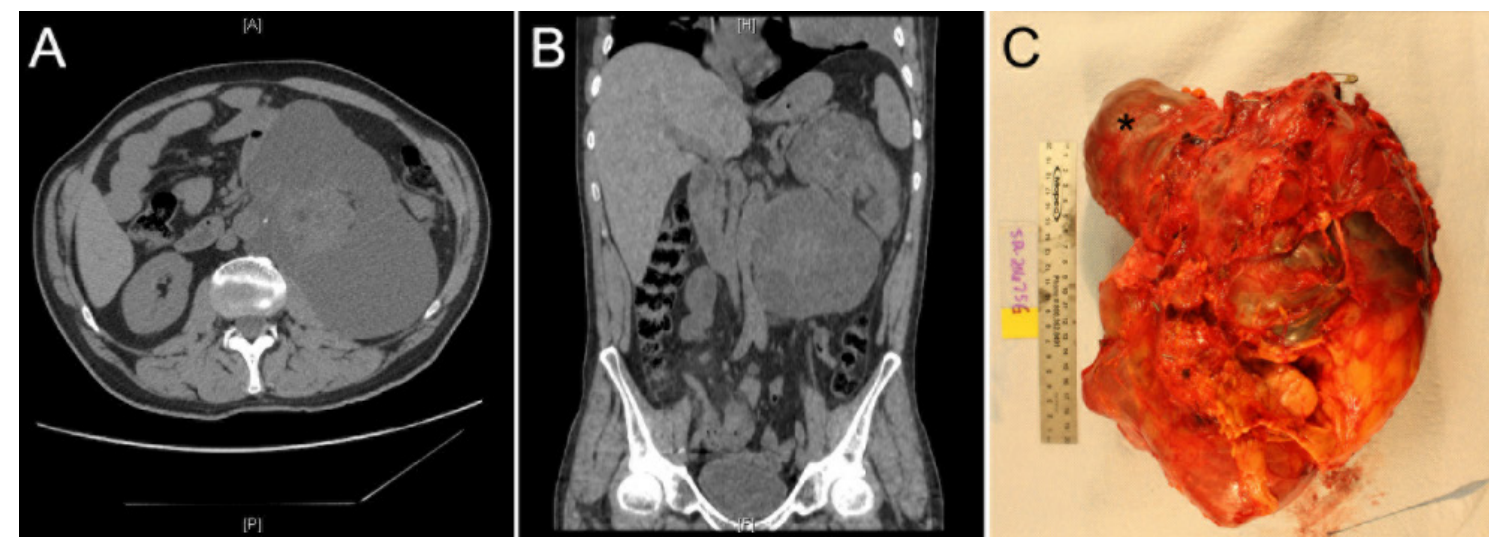

Fig. 1. Resection of retroperitoneal mass, left nephrectomy, and inferior vena caval tumor thrombectomy. A) Axial and B) coronal view of abdominopelvic CT, demonstrating a $19 \times 18 \times 14 \mathrm{~cm}$ heterogenous mass extending from the diaphragm and extending inferiorly to the level of the aortic bifurcation and encompassing the left kidney. C) En bloc removal of left kidney (black asterisk) and retroperitoneal mass.
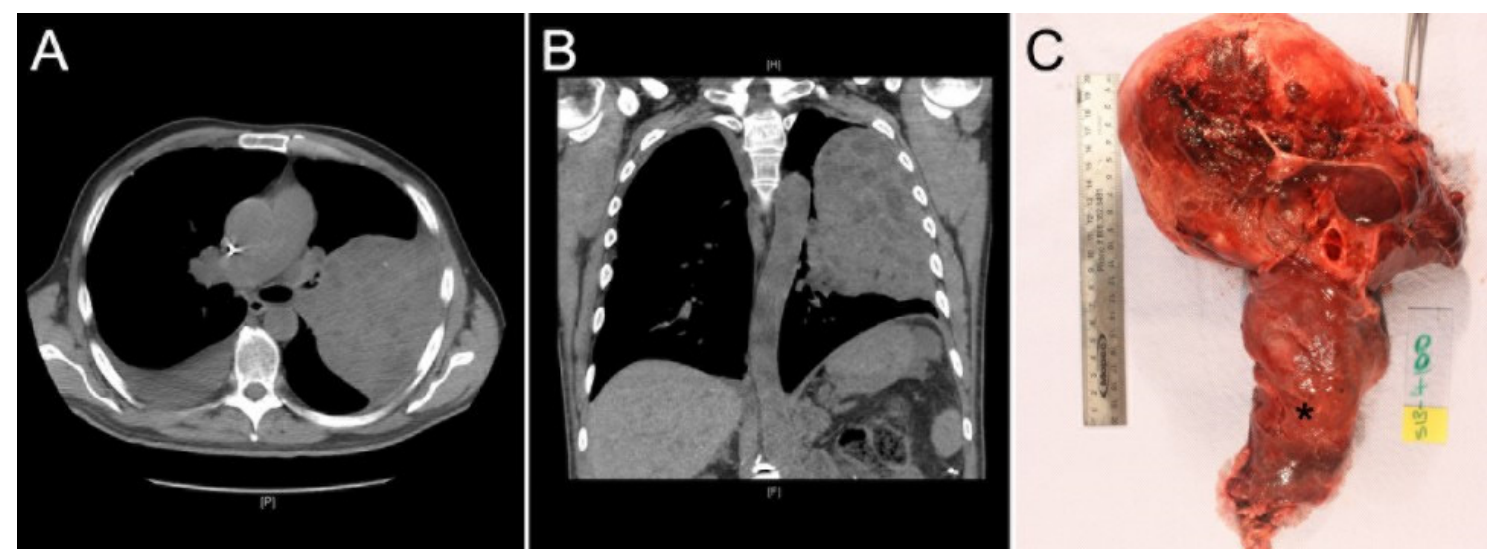

Fig. 2. Pneumonectomy and excision of thoracic teratoma performed 4 months later. A) Axial and B) coronal views of chest CT demonstrating a $14 \times 12 \times 10 \mathrm{~cm}$ heterogenous left hemithorax mass with pleural thickening. C) En bloc removal of thoracic mass with adjacent lung parenchyma (black asterisk).
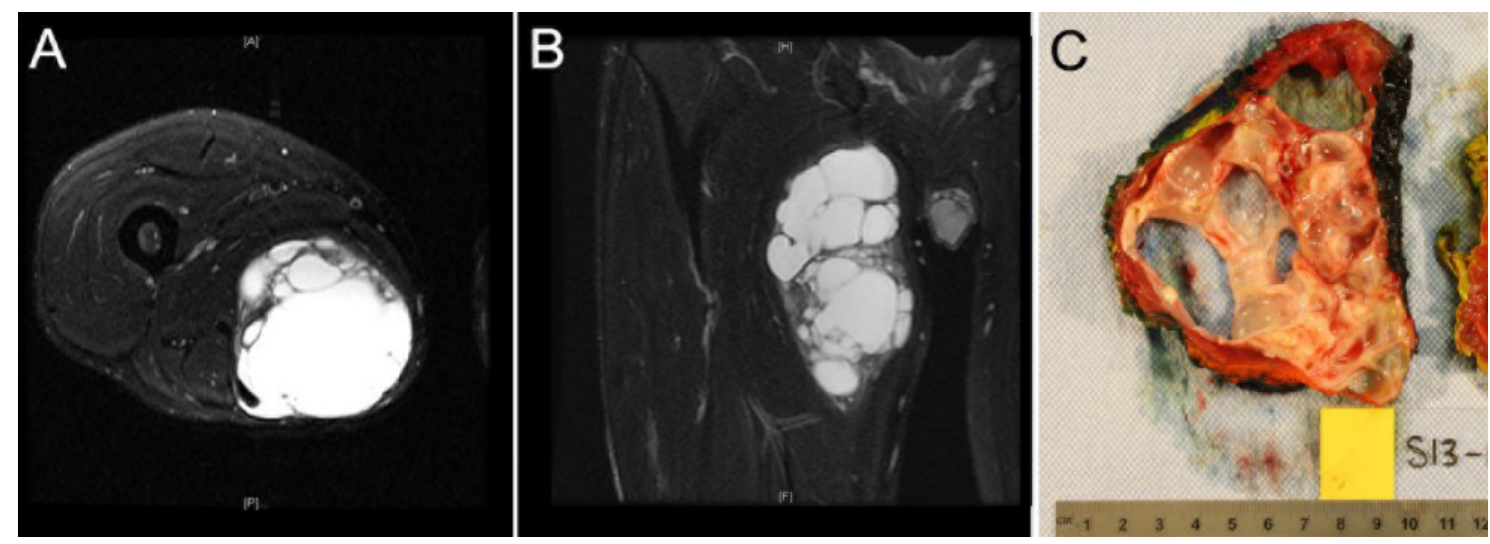

Fig. 3. Excision of right thigh mass performed 8 months following initial retroperitoneal mass resection. A) Axial and B) coronal views of a T2 weighted MRI of the lower extremity demonstrating a $16 \times 10 \times 9 \mathrm{~cm}$ multiloculated intramuscular mass just posteromedial to the gracilis muscle and within the adductor magnus muscle. C) Sectioning of the thigh mass specimen reveals cystic and solid areas. 


\section{References}

1 Sonneveld DJ, Sleijfer DT, Koops HS, Keemers-Gels ME, Molenaar WM, Hoekstra HJ: Mature teratoma identified after postchemotherapy surgery in patients with disseminated nonseminomatous testicular germ cell tumors: a plea for an aggressive surgical approach. Cancer 1998;82:1343-1351.
2 Karam JA, Raj GV: Growing teratoma syndrome. Urology 2009;74:783-784.
3 Spiess PE, Kassouf W, Brown GA, Kamat AM, Liu P, Gomez JA, Tu SM, Tannir NM, Pisters LL: Surgical management of growing teratoma syndrome: the M. D. Anderson cancer center experience. J Urol 2007;177:1330 1334. 